\title{
Hygiene and sanitation: medical, social and psychological concerns
}

I n 2007, over 11000 readers of the British Medical Journal chose the sanitary revolution or, defined more broadly, the introduction of clean piped water and sewerage disposal as the most important medical breakthrough since 1840. ${ }^{1}$ Earlier on, the World Health Organization had called for a decade of water and sanitation to draw attention to the crucial role of hygiene (human behaviour) and sanitation (infrastructural services) in public health, and in 2010 PLOS Medicine published an introductory article titled Hygiene, Sanitation, and Water: Forgotten Foundations of Health as part of a four-part series on water and sanitation. ${ }^{2}$ One of its opening statements read:

A massive disease burden is associated with deficient hygiene, sanitation, and water supply and is largely preventable with proven, cost-effective interventions. ${ }^{2}$

For the past 15 years, the safe disposal of human waste has indeed acquired a status of high priority in public health policies, and the technology of the hygienic toilet is now spreading through poorer parts of the world.

It is indeed remarkable that the medical profession recognizes the crucial importance of a simple and unheroic intervention such as sanitation for the maintenance of health and considers it a bigger step forward than highly advanced medical technologies. Still, the recognition of hygiene and sanitation should not lead to their medical annexation at the expense of other aspects, in particular, their social and psychological implications.

In the history of Western countries, sanitary improvement was not primarily welcomed as medical advance leading to better health; its popularity came first from its appeal to social values such as cleanliness, comfort, esthetics, civiliza-

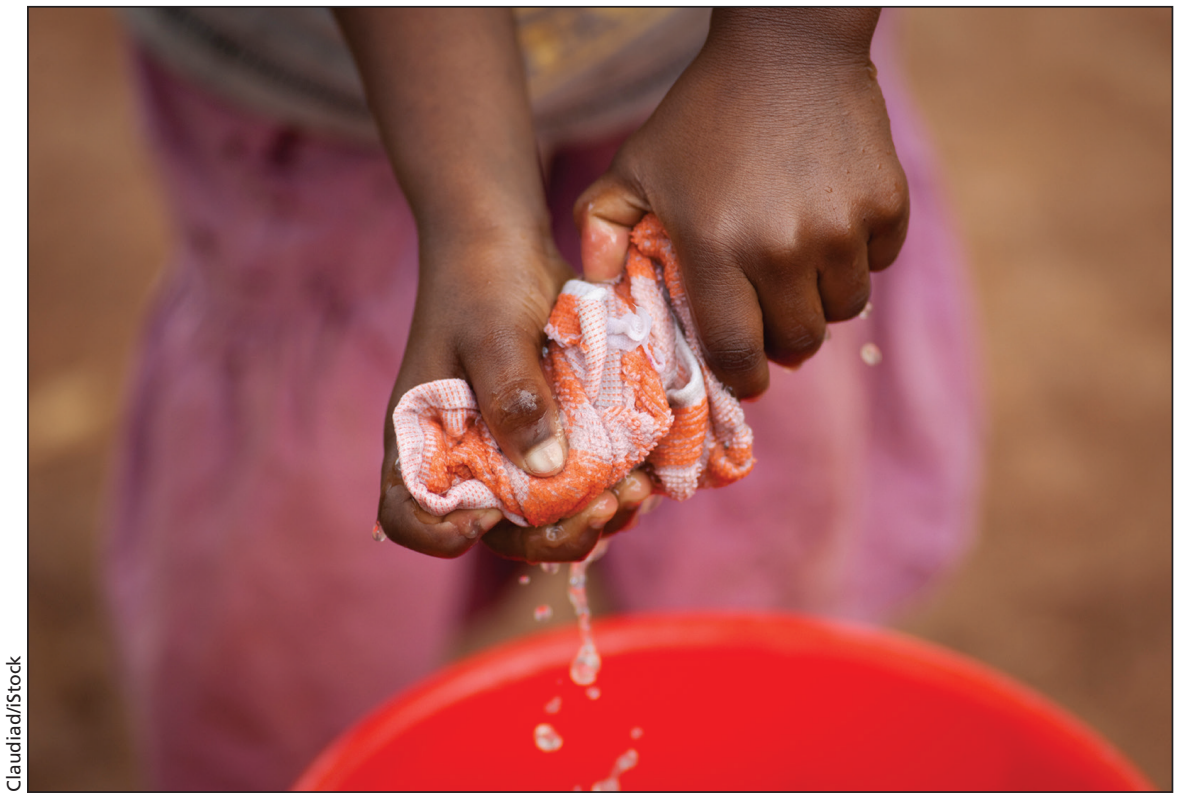

tion, good manners, moral purity, godliness, status and prestige., ${ }^{3,4}$ The same applies to the acceptance of hygienic toilets in countries where modern sanitation used to be the privilege of a few well-to-do citizens. "Stench (the fight against it) and sanitation go hand in hand," writes the historian, Dolly Jørgensen, in her study of sanitary conditions in medieval London. ${ }^{6}$

Hygiene is embedded in a wide and complex set of social values and sentiments. What we call hygiene is linked with concerns about privacy and intimacy, neatness, social prestige, convenience, respect and being civilized. Unhygienic, in contrast, refers to poverty, shame, disgust and invaded intimacy. During my fieldwork in Ghana, I came to realize that cleanliness is the pre-eminent metaphor to express positive appreciation. Clean $=$ beautiful $=$ attractive $=$ good $=$ civilized $=$ respectable. In Ghanaian English, the expression "she is neat" is almost synonymous with "she is pretty," with the connota- tion that she is also beautiful in a moral sense: pure. In short, body cleanliness stands for physical and moral attractiveness, whereas dirt symbolizes physical and moral decay. Dirt, or rather the abhorrence of it, plays a central role in human relations. To say that someone is dirty is almost a rejection of the whole person. Cleanliness of the body (the skin, the orifices, the teeth, the nails) and cleanliness with regard to housekeeping, clothing, or one's children, constitutes a basic condition for a person's attractiveness. Physical beauty and attraction are commonly explained in terms of cleanliness. ${ }^{7}$

Hygienic behaviour, therefore, has more to do with impression management and showing respect to others than with prevention of disease. If we give our house a special cleaning when we expect visitors, we do not do so because we are worried about their health but because we want to make a good impression on them. Washing your hands after defecation - a spear point in present-day sanitation campaigns - 
is mainly a sign of being civilized and respectful. Several studies have shown that people are much less motivated to carry out this act of hygiene when nobody is around to observe their good manners. ${ }^{8}$ Mothers in Ghana show their civilized stature by the cleanliness of their own and their children's appearance, of cooking utensils, and of the house and its immediate surroundings.

A study in rural Benin, West Africa, about people's motives for building a latrine concluded that "health considerations played only a minor role, and had little if anything to do with preventing fecal-oral disease transmission." ${ }^{5}$ The main drives were prestige, well-being, and reasons such as cleanliness, privacy
Douglas, defined dirt as "matter out of place." Her central thesis was that "absolute" dirt does not exist. The same thing or act can be clean as well as dirty. It all depends on the context. Red wine in a glass is fine, but on a dress it becomes dirt. Shoes on the floor (Douglas' own example) are in order, but not on the table. Shaking hands or kissing can be civilized in one situation and outrageous and disgusting in another. Dirt, in other words, is disorder that causes psychological discomfort. Cleaning restores order.

The qualification "out of place" should not be merely understood as a physical or geographical indication (on the floor or on the table). Of more

\section{Dirt is disorder that causes psychological discomfort. Cleaning restores order.}

and convenience. Having a private latrine also attracted people to rent a room in the house, which is a common extra income for house owners. In Ghana, having a decent private latrine proved an important condition for organizing a successful funeral. Funerals are social events where families play host to a large crowd of people who come to pay their respects to the deceased. Some visitors come from far away. For the family, the event is a test of their social standing. If conditions in the house are poor, the funeral guests will gossip and look down on them. However, if the house and the reception are good, they will praise the family. A clean and modern toilet plays a substantial role in that appreciation. The study emphasized that policy-makers should take these aspects into consideration during their social marketing of sanitation. ${ }^{5}$

We will not understand hygiene if we do not also discuss disgust. Dirt can be disgusting; removing it is, therefore, not only a social act but also a psychological and emotional one. But what is dirt and why does it cause disgust? In a classic essay, the anthropologist, Mary importance is its relational aspect. The wine can still be in the glass and yet be dirty because someone else has drunk from it. The identity of that other person is crucial for the emotional reaction. One person may cause disgust, whereas another person will cause much less or no disgust at all. For some lovers, drinking from one glass even increases the pleasure. The same applies to dealing with matters that we are inclined to consider as absolute dirt (e.g., feces). Cleaning one's little baby is not a disgusting experience for most people; however, a confrontation with the feces of another person may be extremely disgusting. The decisive difference between people who do and do not cause disgust is intimacy. The most forceful cause of disgust is not the matter or act itself, but the degree of undesired intimacy that it brings about.

Disgust, according to some scientists, is a natural instinct - a product of our evolution - that protects us against disease. But that is too simple. Disgust is an impulse to restore order. It is an emotion that sets our boundaries and protects our intimate privacy. This may have favourable health effects, but the opposite may also happen. One may acquire HIV from one's lover. A study in Uganda showed that people considered injection needles dirty if they had been used by outsiders and clean if they had been used within the family. ${ }^{10} \mathrm{~A}$ hygienic toilet can be dirty because it is also being used by someone with whom one does not or should not share intimacy. If medical sanitation efforts clash with social values or emotional concerns, they are unlikely to be accepted. Or, to put it more positively, sanitation and hygiene are physical, social and psychological phenomena that may also lead to health improvement.

Sjaak van der Geest MA PhD

Professor Emeritus of Medical

Anthropology, Department of Sociology and Anthropology, University of

Amsterdam, Amsterdam, The Netherlands

\section{References}

1. Ferriman A. BMJ readers choose the "sanitary revolution" as greatest medican advance since 1840 [news release]. BMJ 2007;334:111.

2. Bartram J, Cairncross S. Hygiene, sanitation, and water: forgotten foundations of health. PLoS Med 2010;7:e1000367.

3. Goudsblom J. Public health and the civilizing process. Milbank Q 1986;64:161-88.

4. Corbin A. The foul and the fragrant: odor and the French social imagination. Cambridge (MA): Harvard University Press; 1988.

5. Jenkins MW, Curtis V. Achieving the 'good life': why some people want latrines in rural Benin. Soc Sci Med 2005;61:2446-59.

6. Jørgensen D. The medieval sense of smell, stench, and sanitation. In: Krampl U, Beck R, RetaillaudBajac E, editors. Les cinq sens de la ville du Moyen Âge à nos jours. Tours (France): Presses Universitaires François-Rabelais; 2013.

7. Van der Geest S. Akan shit: getting rid of dirt in Ghana. Anthropol Today 1998;14:8-12.

8. Cahil SE, Distler W, Lachowetz C, et al. Meanwhile backstage. Public bathrooms and the interaction order. J Contemp Ethnogr 1985;14:33-58.

9. Douglas M. Purity and danger: an analysis of concepts of pollution and taboo. Harmondsworth (UK): Penguin; 1966.

10. Birungi H. Injections as household utilities: injection practices in Bugosa, Eastern Uganda. In: Etkin NL, Tan ML, editors. Medicines: meanings and contexts. Quezon City (Philippines): HAIN; 1994.

\section{CMAJ 2015. DOI:10.1503/cmaj.150588}

"Wherever the art of medicine is loved, there is also a love of Humanities." Hippocrates 